\title{
In this Issue: Authors and Articles
}

Mitroff and Mason's "Logic for strategic management"

Strategic management is often perceived as a set of corporate responses intended to cope with the increasing environmental complexity and turbulence. But corporate strategy, perceived by an observer as a set of external responses, is in fact an outcome of internal processes of communication, argumentation and debates among human participants within the firm. As such, strategy is only partially identifable as a consciously designed set of measures; its larger parts represents spontaneous and so far mostly unpredictable unfoldment of these internal debates. Mitroff and Mason drive this point home quite clearly and are taking the first step towards this deeper, internally evolved understanding of strategic behavior.

Internal debates, conversations and negotiations are to a certain degree autonomous, that is, partially independent of the external environment. The resulting strategy either matches the environmental complexity and becomes 'correct', or it does not, it fails, and a learning fedback loop sets in, affecting again the internal debates. This view is of course quite different from its reductionistic counterpart insisting on an imposed mechanistic design (often with the help of an external consultant) of a 'strategy'. Implementability then becomes crucial and often fatal problem of such strategic management philosophy.

Mitroff and Mason draw our attention to the fact that strategic management cannot be separated from the broader framework of human systems management. We have to avoid the erroneous logic of the past which insisted that firms do have utility functions or objectives. We now know that it is the $o b$ server who interprets firm's behavior as if it maximized profits or utility and followed objectives; as if it had a strategy. To realize that a strategy is an observer-dependent interpretation of internal dialogues and debates will go a long way towards our understanding of the phenomenon of strategic management.

Mitroff and Mason call for and attempt to employ 'context dependent' logic, dealing with purposeful components or entities in the best Churchman-
Ackoffian tradition. Individual goal-seeking entities, through their interaction, give rise to a strategy and their purposes and goals, as well as the interaction, are reversely affected by the emerging strategy. The entities themselves change, not only in response to the external environmental disturbances, but also within the new strategy framework they themselves created through their interaction. An expanded concept of 'stakeholders', i.e. those claimants who have a vested interest in a given problem and its solution, is used to describe this contextually changing set of entities. Yet unsolved, remaining problem is the identification of 'hidden', unidentified but possibly influential categories of stakeholders. The authors are well aware of this potential deficiency and difficulty.

The process of strategy formulation is not sequential, linear and iterative. Rather, it emerges from a circular, closed and interdependent concatenation of stakeholders engaging in an continuing 'conversation'. Such closure implies the relative autonomy of a strategy-formation process while the external environment influences provide only perturbations to its essentially autonomous, self-referential course of action. These perturbances affect the 'conversation' until its circular progression gets 'in phase' or 'locks' itself in' the environmental flow of perturbations or fluctuations. Again, the reader is invited to ponder the distinction of this viewpoint from the mechanistic-engineering treatment of environmental influences as direct informational inputs into a sequential process of strategy formation. This view is not explicit in Mason-Mitroff's approach but it emerges implicitly from their stated assumptions.

The readers should be aware that this paper is not about strategic management per se but about the underlying logic of the process of strategic management. It is a program for research and strategic management philosophy formation. It calls for leaving the 'habitual domains' within which strategies are formed and implemented. It address the essential dynamics of the strategic process, its contextual dependency and recursively changing set of 'stakeholders', their claims and attributes.

As stated elsewhere in this issue, Human Systems Management intends to assert itself as one of the 
major 'stakeholders' in developing a useful, humanoriented theory and practice of strategic management. Mason-Mitroff's paper represents the first manifestation of our claim.

\section{Deutsch's "Technology and social change"}

An increasing number of social researchers and thinkers are expressing their views with respect to the impact and role of technology in currently emerging societal transformations. Karl Deutsch draws readers' attention to 'information capital' and its functions in modern, technologically advancing societies. Yet, he dismisses the relatively empty concept of 'postindustrial' society and insists on a continuing need for evolving and maintaining considerable industrial foundations.

Professor Deutsch, born in pre-war Czechoslovakia, has been a keen and experienced student of problems of nationalism, politics, and power throughout his rich academic career. Also in this article, Deutsch explores the existing weakening of class appeal and eventual decrease in nationalism as the likely consequences of the described societal and technological changes.

One of the key concepts in Deutsch's analysis is the dual nature of capital: tangible, material 'hardware' and intangible, informational 'software'. These types of capital are complementary and their combination forms the basis of technology and innovation. It is argued that since the times of Karl Marx the proportion of the 'invisible' capital has been steedily rising in the mix. When the material part of capital dominated, the ownership of the means of production continued to be of utmost importance: such capital, once transfered, cannot be possessed. In contrast, the 'software' capital can be repeatedly transferred without necessarily losing its possession. As information capital is becoming the dominant means of production, the old marxist doctrine about the primacy of the ownership of the means of production loses its relevancy and vitality.

Deutsch then goes on to discuss seven major streams of change which are at the base of current societal transformations. Some of them are debatable, as for example the linear projections about the doubling of populations until the year 2075. Such forecasts were often based on simple-minded statistics and did not take into account such important counterveiling trends as women's instincts, development, chemicals, changes in attitudes and hope. One would also expect that more than a short paragraph would be devoted to the effects of change in less developed countries.

On the other hand, Deutsch's thesis about declining differentials in global military and political power seems to be further supported by recent history. U.S. inability to cope with international problems (Iran, Palestine, India, Western Europe), Soviet inability to subdue Afghan tribesmen, German and French shifts of allegiance from the U.S.A. to Soviet Union, and so on, indicate the increased ambiguity and turbulence at the time of decreasing differentials of power.

Deutsch concludes his essay by emphasizing that a great degree of political and social freedom is necessary for the production of knowledge. There cannot be any scientific-technical 'revolution' which would be fully planned and controlled by political centers of power. Acquisition of knowledge, being a combinatorial process, thrives on innovation, unpredictable new combinations, and some degree of built-in slack or redundancy. Deutsch concludes that even the mightiest government cannot control knowledge and its acquisition exactly, with or without political police.

\section{Rosenthal's "Applied urban research"}

Applied social research, as selected, sponsored and evaluated by the National Science Foundation, is subjected to Stephen Rosenthal's insightful analysis. The author is an experienced consultant and expert on public service delivery systems. He has chosen two fascinating case studies, Managing Vandalism and Property Tax Policy, to demonstrate his notion of 'policy-relevant' social research. Measurement of relevancy is extremely difficult and ambiguous task. Yet, Rosenthal seems to be getting close to the understanding of its multi-criteria, multi-agent, multivalued character.

Kenneth R. Hammond, in a Short Communication in this issue of HSM, is expressing the same awareness of multiple objectives and values involved in public policy decision making. Hammond is critical of taking an easy way out: returning to singular emphasis on a preferred single value, disregarding the value systems of others or engaging in endless disputes of engineer's facts. Rosenthal feels strongly that instead of optimizing some sort of aggregate public welfare function (or utility function), the task of public policy 
management is to balance competing interests and objectives of multiple participants (to balance multiple criteria).

There are many significant observations and insights interspersed through the rather lengthy descriptions of the two case studies. The reader is well advised to look for them actively and to appreciate their inconspicuous emergence.

For example, the concept of multiple leadership implies that a variety of leadership functions, not one leader, are needed during different stages of a project lifetime. More importantly, such sharing and complementarity of leadership functions comes naturally to people. Another pervasive concept is that of trust in decision making. A trust? This must sound strange to generations of 'strategists' nourished by prisoners' dilemma of game-theoretical modeling of deception. Rosenthal found that trust is a crucial and one of the most important factors involved in multi-agent decision making. People do accept the risk of trusting one another.

Rosenthal also discusses 'analytic capacity' and 'managerial insight' as potentially valid objectives of urban research. Can 'insights' be a more reasonable research goal than 'solutions'? Analytic capacity is closely connected with the process of research, an ongoing controlled social experiment, allowing adaptive learning process to take place. Managerial insight is generated by research product although not in the traditional solution sense. Both case studies argue quite persuasively for more action-oriented research, closer interaction between managers and researchers, and greater appreciation of the existing decision. making environments and circumstances.

Many successful projects, in terms of Rosenthal's relevancy criterion, were not based on the performance record of the researchers involved. One can recall recent discussions in Science arguing for peer reviews based on 'scientific record' as the sole criterion for funding a given project or researcher. Is the record of performance irrelevant at least for some classes of applied social research?

At this point the reader will realize that Rosenthal's conclusions are ambitious, unorthodox and strategically significant. Yet, the author is quite skeptical about the chances of implied re-orientation of scientific and governmental institutions interface. The editors of HSM are less skeptical and there is hope that a significant and 'policy-relevant' debate will be spurred by this article.

One final note. There is a strong implicit and explicit argumentation for systems approach in Rosenthal's paper. Clusters of interrelated projects or entire programs, not the distinct individual projects, are to be subjected to improved coordination and management. One can recall Senator Proxmire's "Golden Fleece Award", pinpointing a project here and a project there, separated from the context, and hoping to affect the quality of applied research through such isolated 'nitpicking'. The futility of such non-system efforts makes a Golden Fleece material par excellence.

\section{Hellriegel and Slocum's "Preferrred organizạtional designs"}

At the extremes, managers often approach their problems either in a logical, rational, sequential and quantitative mode, or in a perceptive, intuitive, simultaneous and qualitative mode. The two professors from Texas now confirm that there is no one best problem-solving style: neither mode is to be preferred per se. It appears that to approach the problems of reality in their full complexity requires a conscious enhancement of both ends of the analytical-intuitive continuum of human problem-solving styles:

Hellriegel and Slocum are well experienced in conducting executive development programs on organizational behavior. Naturally, they do not limit themselves to only characterizing the different problemsolving styles but attempt to relate them to various organizational designs. That is, particular styles may be better suited to certain positions and roles in an organization than others. If one could identify the style with reasonable accuracy (and if the style itself would be relatively stable), then one could prefer sensation-thinking types as statisticians, accountants or financial analysts while intuition-feeling types as personnel, sales or training managers.

The above hypothesis of the best 'fit' between problem-solving style and a position within an organization is by no means asserted by the authors. It is only implicit in their article and its discussion is mostly avoided. Curious and unsatisfied reader is advised to ponder Manfred Kochen's Editorial, appearing also in this issue.

Organizational design must be sensitive to both the external and the internal environment of an organization. Individual differences among managers, and their different problem-solving styles, are one of the crucial characteristics of the internal environment. This is where the Hellriegel-Slocum emphasis 
become obvious and significant.

An important hidden assumption behind the Hellriegel-Slocum study is the old Jungian contention that there are relatively stable personality types characterized by the dominance of one of four psychological functions: thinking, feeling, sensation or intuition. This avoids the problems of observed alternating and switching between styles in dependency on different situations and contexts. Many people adopt such 'no style' approach as their particular style. Also, learning, training, role playing and deception with respect to style would favor a dynamic rather than a static notion of style.

Individual with different problem-solving styles are expected to prefer working in different ideal organizational settings. They would perhaps differently describe their notion of an ideal organization. Even more likely, individuals with the same problem-solving styles would exhibit a high degree of congruence in their descriptions. That is what Hellriegel and Slocum found.

There was an extremely successful executive who used sensation-thinking style in evaluating the projects submitted by his subordinates, intuition-thinking style in making his new investment decisions, sensation-feeling style in troubleshooting and intuitionfeeling style in hiring his secretaries. The point is: not only do different people approach the same problem differently, but also the same person will approach different problems differently. Because, as experienced managers know, the only right way to do it is to do it right.

A manager of the future must possess the full repertoire of problem-solving styles, be flexible in using them in appropriate situations and consciously enhance their interdependency and synergic effect. That seems to be a message of this article.

\section{Sandkull's "Mismanagement of people"}

Bengt Sunkull provides the readers of HSM with a glimpse of the kind of thinking which is typical for some Swedish researchers with respect to workers' participation and industrial democracy experiments. The state of Swedish industry, its lack of entrepreneurship and innovation, large-scale strikes, and dissatisfaction, are the most recent magnifications of the failure of these experiments.

Sandkull talks about the importance of workers and their unions when facing the upcoming techno- logical changes in the industry. Computerization, electronics, robotics, etc., and their control, understanding and mastership, are becoming much more important factors than formal ownership of production facilities. Workers' response: strikes, absenteeism, low productivity and quality, are irreversibly' speeding up the implementation of the new technology.

Sandkull finds himself facing a strange dilemma indeed: he has to defend old-fashioned, ordinary mechanical assembly lines, no matter how tedious or degrading, as they allow even the rudimentary vestiges of understanding of the production process to be retained by the workers. Computerization and robotics remove direct access of workers to such understanding and put the decision making and control power squarely in the hands of managers.

For example, six years ago Volvo experimented with small teams of workers, working at their own pace, in putting automobiles together. Absenteeism and labor costs have been soaring. Volvo has now established itself as the European leader in the use of industrial robots. The trend is definitely towards robotization.

The main cause of absenteeism in Sweden seems to be the total conflict between the interests of industries and governmental politics. One of the 'social reform' bills enables a worker to call in sick for up to eight straight days without providing any proof of a medical examination. Nobody should work if they feel ill, and nobody knows better than a worker if he is not feeling well. Industry response: robots do painting, pressing, engine block and gear-box assembly, body welding - and they show up in work every day.

Sandkull concludes that despite the formal rights, unions are still at the mercy of executives' presentations and interpretations. It is the managers who make decisions, and these decisions are "suited to capital interests". But workers need to participate in management and thus the "function of management has to be dissociated from managers". How is this to be achieved? Through a continuing reasoned challenge and contests which would transform the prevailing order. Indeed such a transformation process has already started in Sweden - the outcomes are very difficult to predict.

Sandkull's view is clearly marxist ("Industrial firms are the tools of their masters to achieve profits and accumultate capital"). He observes that some companies are bound to be lost in competitive 
struggles and insists that major losers are the employees. There are many existing systems where no firms are allowed to go bankrupt, and where even the most backward and inefficient firms are sheltered by the government in order to maintian full employ- ment. The workers are major losers there as well. The dilemma remains. However, technology, as an integral part of human culture, cannot be separated from humanism. 